\title{
The Theory of Planned Behavior and Parental Involvement: A Theoretical Framework for Narrowing the Achievement Gaps
}

\author{
Yazan Alghazo, Ph.D \\ Department of Humanities and Social Sciences, Prince Mohammad Bin Fahd University, Alkhobar, Kingdom of Saudi Arabia
}

\begin{abstract}
This theoretical paper presents a theoretical model that shows the effect of cultural aspects mentioned in the theory of planned behavior, namely, subject norms on parental involvement behaviors of parents. The paper reports on the findings of several studies that demonstrate the relationship between parental involvement and student achievement in school in several cultural contexts. The findings and conclusions of this theoretical paper suggest that emphasis needs to be placed on increasing parental involvement in children's education as a tool to decrease achievement gaps between students. More specifically, parental involvement can be seen as a tool to overcome achievement gaps caused by socioeconomic differences between students' families.
\end{abstract}

Keywords: Parental Involvement, Achievement Gaps, Theory of Planned Behavior.

\section{Theory of Planned Behavior}

Ajzen's (1991) theory of planned behavior is "a theory designed to predict and explain human behavior in specific contexts" (p.181). The theory focuses on the motivational reasons that lead to higher intentions to perform a behavior on the basis that "the stronge $r$ the intention to engage in a behavior, the more likely should be its performance" (Ajzen, 1991, p.181). According to the theory of planned behavior, one should understand the reasons that lead to intentions in order to be able to predict future involvement in a behavior.

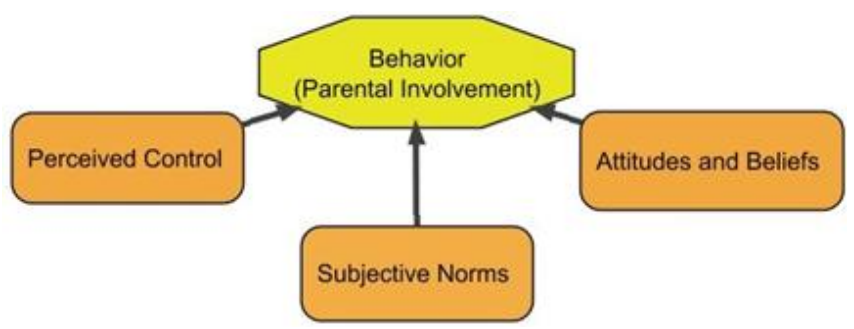

Figure 1: Theory of Planned Behavior.

The Theory of Planned Behavior (TPB) sets a model for humans' actions in which intentional behavior is determined by: (a) attitudes and behaviors, (b) subjective norms, and (c) perceived controls (see Figure 1.). Attitudes and behaviors include feelings and attitudes towards a certain behavior. Believing that a certain behavior has positive outcomes will surely lead to more intention to perform that behavior. Subjective norms are the opinions of the people surrounding the person wishing to engage in a certain behavior, which can lead to peer pressure and social pressure, both of which can lead to one's higher intentions to perform a certain behavior. Finally, perceived control is one's own perception of his/her ability to perform a certain behavior; perceived control contributes to both having the intention to perform certain behaviors as well as whether or not the person would actually perform the behavior (Ajzen, 1991).

The theory of planned behavior can be used to explain and predict the behavior of parental involvement in children's schooling. Perry and Langley (2013) suggest using Ajzen's
Planned Behavior Theory; they argue that the theory of planned behavior is "versatile enough to account for the dynamicand complex nature of paternal engagement" ( $p$. 181). Furthermore, according to Bracke and Corts (2012), parents' culture, having examples of parental involvement, and having role models or neighbors that do or do not get involved in their children's education are all factors that help shape the "subject ive norms about the role of parents in education" (p. 194).

\section{Theoretical Models of Parental Involvement}

Hoover-Dempsey and Sandler (1995) provided a theoretical definition for researching parental involvement. Their theoretical model defines parental involvement according to three main points: (1) why parents become involved in their children's education,(2) how parents choose specific types of involvement, and (3) why parental involvement has a positive influence on students' educational outcomes. According to Fan and Chen (2001), this theoretical framework "promises to be more than a typology for parental involvement, because it not only deals with specific types of parental involvement, but more importantly, it attempts to explain why parents choose to be involved, and what the mechanisms are through which parental involvement exert[s] positive influence on students' educational outcomes." (p.3)

Epstein and Dauber (1991) proposed a model that distinguishes six different types of parent-school connections: First, "Basic obligations of families" (p.290) which refers to the parents' role in raising their children and preparing for their school years by providing a suitable home environment and conditions that foster their children's growth and development throughout their school years. Second, "Basic obligations of schools" (p.290) which refers to the role of schools in communicating with the parents about the academic progress of their children and providing constant feedback to parents about their children's schooling and development. Third, "Involvement at school" (p.290) which refers to parents' visits and volunteer work at the school to help support their children with both academic and 


\section{International Journal of Science and Research (IJSR) \\ ISSN (Online): 2319-7064 \\ Index Copernicus Value (2013): 6.14 | Impact Factor (2015): 6.391}

extracurricular activities; Epstein and Dauber (1991) suggest that schools can improve this type of involvement by offering flexible schedules that allow more families to be involved. Fourth, "Involvement in learning activities at home" (p.291) which includes parents being involved in their children's homework and learning activities through the guidance of a school's teachers; this promotes collaboration between the teachers and parents allowing them both to keep track of children's development and academic growth. Fifth, "Involvement in decision-making" (p.291), which refers to active participation in parent-teacher associations (PTAs) and other community support groups. Sixth, "Collaboration and exchanges with community organizations" (p.291) which refers to the overall collaboration among parents, schools, and other organizations that share the responsibility and interest in children's education through providing different services outside of schools such as providing health care or child care services.

Researchers have investigated Parental Involvement through several theories such as identity theory,the paternal investment theory, the theoretical model of father involvement, the conceptual model of responsible fathering, the ecological theory, the role theory and the social exchange theory (Perry \& Langley, 2013). However, Perry and Langley (2013) argue that those theories have "limited applicability with regard to explaining and predicting paternal involvement" (p.181) because such theories assume that active involvement of parents only relies on the parents' will and desire to be involved in their children's education. As an alternative theory to help explain and predict parental involvement, Perry and Langley (2013) suggest using Ajzen's Theory of Planned Behavior (TPB); they argue that TPB is "versatile enough to account for the dynamicand complex nature of paternal engagement" (p. 181).

This theoretical framework was mainly guided by Ajzen's (1991) theory of planned behavior to help explain the motivation for Parental Involvement and the factors that affect parents' levels of involvement. The theory of planned behavior sets a model for understanding and predicting humans' intentional behaviors in which intentional behavior is determined by: (a) attitudes and behaviors, (b) subjective norms, and (c) perceived controls. Figure (2) explains the overall theoretical framework for this paper. The theory of planned behavior (demonstrated in Figure 1.) provides additional factors, such as subjective norms, attitudes and beliefs, and perceived control that might also affect parental involvement and explain variations in parents' levels of involvement.

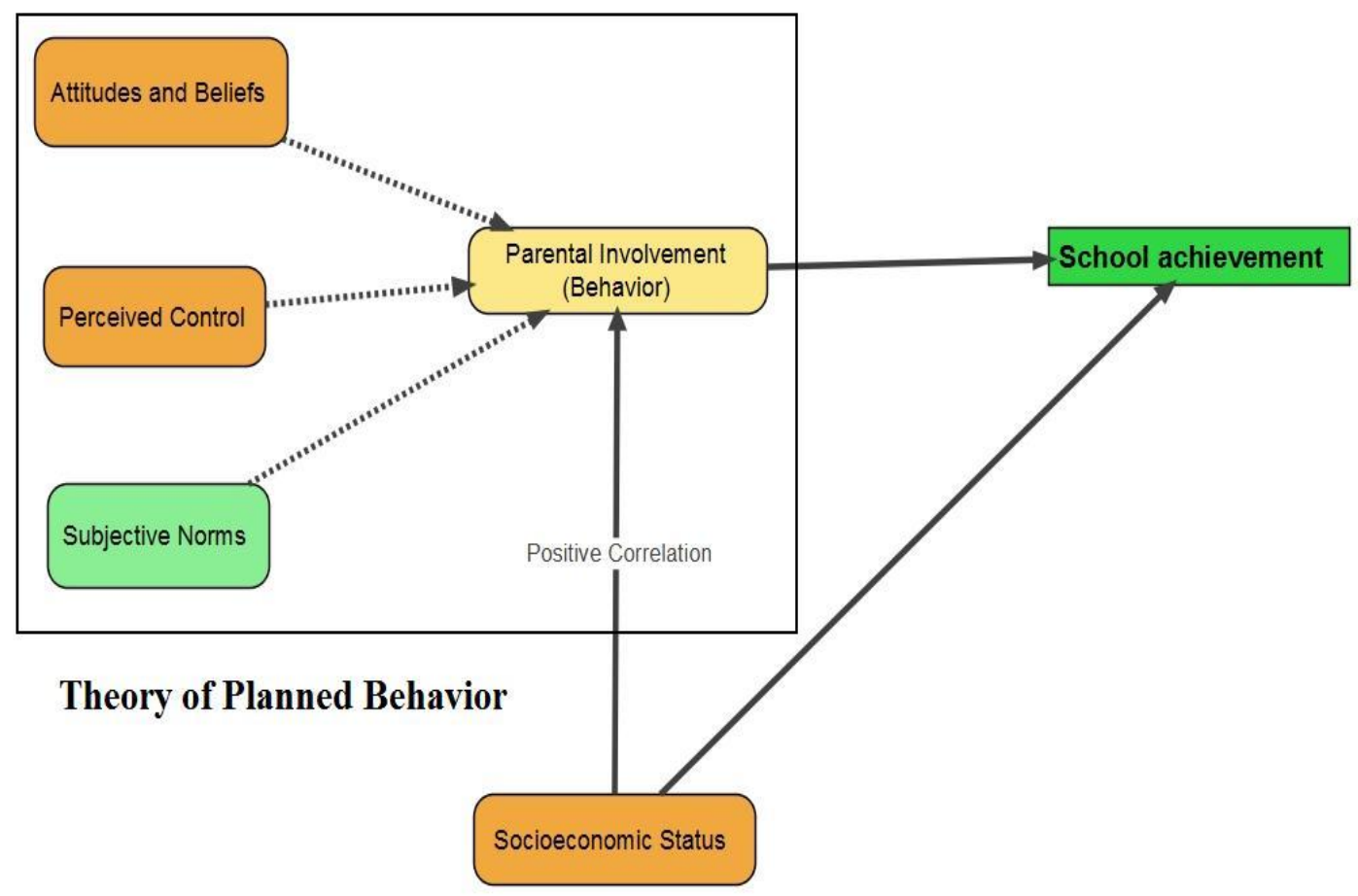

Figure 2: Theoretical Framework

Specifically, we focus on the influence of "Subjective Norms" on certain human behaviors, namely, parents' involvement in their children's education. Factors that help shape the "subjective norms about the role of parents in education" are parents' culture, having examples of parental involvement, and having role models or neighbors that do or do not get involved in their children's education (Bracke\&Corts, 2012, p. 194). The Theory of Planned behavior helps explain some of the cultural aspects that account for differences between parental involvement levels of parents in the different countries.

\section{Conclusion}

Parental involvement has been shown to positively correlate with children's academic achievement (Barnard, 2004; Bower, 2011; Desimone, 1999; Hill \& Craft, 2003; Hill \& Taylor, 2004; Zellman\& Waterman, 1998), and, as a result of these findings, researchers have suggested that parental 


\section{International Journal of Science and Research (IJSR) \\ ISSN (Online): 2319-7064 \\ Index Copernicus Value (2013): 6.14 | Impact Factor (2015): 6.391}

involvement can be used as a means to decrease achievement gaps across different groups of students (Bower, 2011; Jeynes, 2011; Zellman\& Waterman, 1998). It is, therefore, essential that researchers investigate the reasons behind the different levels of parental involvement in order to inform school reformers about approaches of increasing parental involvement and, subsequently, improving student achievement and decreasing achievement gaps.

Alghazo and Alghazo (2015a, 2015b) conducted studies on Jordan and the United States in order to compare the reasons for parental involvement in both countries, as well as any differences in the cultural effect on parents' choices to be involved in their children's education. Their findings revealed that, in Jordan, Socioeconomic status had no effect on parental involvement levels. They explained this finding by the strong cultural beliefs or subjective norms that believed in the importance of parental involvement in children's education.

Parental involvement was also shown to have benefits beyond improving student achievement at school (Bower, 2011). For example, parental involvement increases social capital and provides additional resources to students, which increases their academic success (Bower, 2011; Lee \& Bowen, 2006).

In conclusion, based on the findings of previous studies discussed in this paper, it is recommended that parental involvement be emphasized as a tool to counterpart the effect of socioeconomic status on student achievement. If schools are able to increase parental involvement levels in their children's education, the negative effect of low socioeconomic status could be reduced, and thus, the achievement gap between students from different socioeconomic statuses could be narrowed.

\section{References}

[1] Ajzen, I. (1991). The theory of planned behavior. Organizational Behavior and Human Decision Processes, 50, 179-211.

[2] Alghazo, Y., \& Alghazo, R. (2015). The effect of parental involvement and socioeconomic status on elementary students' mathematics achievement. Journal of Humanities and Social Sciences, (1)5. 521-527

[3] Alghazo, Y., \& Alghazo, R. (2015). The relationship among parental involvement, socioeconomic status, and mathematics achievement in Jordan. International Journal of Science and Research, (4)10.1306-1311

[4] Barnard, W. (2004). Parent involvement in elementary school and educational attainment. Children and Youth Services Review, 26(1), 39-62. doi:10.1016/j.childyouth.2003.11.002

[5] Bower, H. (2011). Can the Epstein Model of Parental Involvement work in a high-minority, high-poverty elementary school? A case study. Professional School Counseling, 15(2), 77-87.

[6] Bracke, D., \&Corts, D. (2012). Parental involvement and the Theory Of Planned Behavior. Education, 133(1), 188.
[7] Desimone, L. (1999). Linking parent involvement with student achievement: Do race and income matter? Journal of Educational Research, 93(1), 11.

[8] Epstein, J. L., \& Dauber, S. L. (1991). School programs and teacher practices of parent involvement in inner-city elementary and middle schools. The Elementary School Journal, 91(3), 289-305. doi:10.1086/461656.

[9] Fan, X., \& Chen, M. (2001). Parental involvement and students' academic achievement: A meta-analysis. Educational Psychology Review, 13(1), 1-22.

[10] Hill, N. E., \& Craft, S. A. (2003). Parent-school involvement and school performance: Mediated pathways among socioeconomically comparable African American and Euro-American families. Journal of Educational Psychology, 95(1), 74.

[11]Hill, N. E., \& Taylor, L. C. (2004). Parental school involvement and children's academic achievement. Current Directions in Psychological Science (WileyBlackwell), 13(4), 161-164. doi:10.1111/j.09637214.2004.00298.

[12] Hoover-Dempsey, K. V., \& Sandler, H. M. (1995). Parental involvement in children's education: Why does it make a difference? Teachers College Record, 97(2), 310-331.

[13] Jeynes, W. (2011). Parental involvement and academic success. New York: Routledge.

[14] Lee, J., \& Bowen, N. K. (2006). Parent involvement, cultural capital, and the achievement gap among elementary school children. American Educational Research Journal, 43(2), 193-218. doi:10.3102/00028312043002193

[15] Perry, A., \& Langley, C. (2013). Even with the best of intentions: Paternal involvement and the Theory of Planned Behavior. Family Process, 52(2), 179-192. doi:10.1111/famp.12013

[16]Zellman, G. L., \& Waterman, J. M. (1998). Understanding the impact of parent school involvement on children's educational outcomes. Journal of Educational Research, 91(6), 370. 